\title{
Academic receives award for improving child oral health
}

The International Association for Dental Research (IADR) - the largest scientific association that focuses on research in the field of dentistry - has recognised an academic from Queen Mary University of London for advances in improving oral health in children.

The IADR has announced that Cynthia Pine, Professor in Dental Public Health at the Queen Mary's Institute of Dentistry, is the 2018 recipient of the IADR's E.W. Borrow Memorial Award.

Sponsored by The Borrow Foundation, the E.W. Borrow Memorial Award recognises research in oral health prevention for children, with an emphasis on using fluoride in different formats to prevent tooth decay.

The award was presented as part of the IADR's General Session annual conference held at the ExCeL London Convention Centre from 25 to 28 July 2018.

Professor Pine, from Barts and The
London School of Medicine and Dentistry, has carried out research focused on oral health promotion for children, particularly

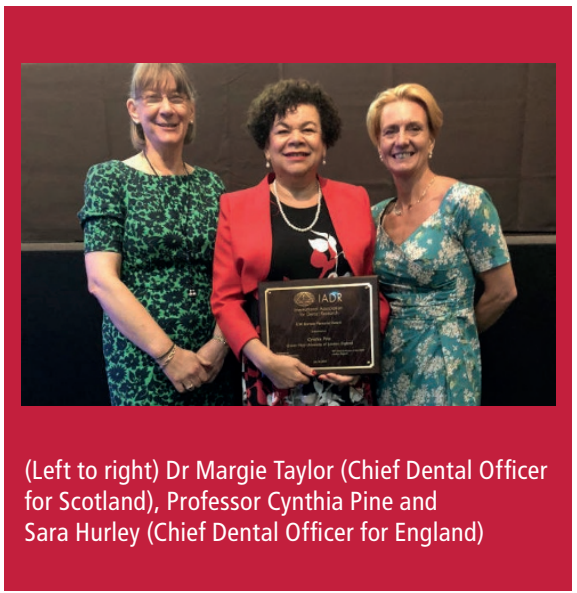

the prevention of childhood dental caries or decay. She works with disadvantaged communities nationally and internationally with the goal of reducing health inequalities.
The IADR said her research in the measurement of caries in children had informed national and international quality standards while also helping develop interventions designed to improve parents' key dental health related behaviours.

As well as holding a ten-year position as Director of the World Health Organisation Collaborating Centre for Research in Oral Health of Deprived Communities (2003-2013), Professor Pine received the European Organisation for Caries Research of the ORCA Prize 2015, and received a CBE (Commander of the British Empire) for services to dentistry from the Queen.

Professor Pine said: 'I am delighted to receive this award and I would like to thank my research collaborators and the many thousands of families who have worked with us in our research on the prevention of childhood dental caries. It's a great honour to have our work recognised by the IADR.'

\section{Nutrition and oral health collaboration celebration}

The World Health Organisation (WHO) and Newcastle University recently held an event to celebrate 21 years of collaboration. The event in London was held on 23 July 2018 to celebrate 21 years of Newcastle University School of Dental Sciences hosting the WHO Collaborating Centre for Nutrition and Oral Health.

The programme was put together in collaboration with the Global Oral Health Inequalities Research Network of the International Association of Dental Research (IADR) to address the UN Sustainable Development Goals through nutrition and oral health.

Paula Moynihan, Professor of Nutrition and Oral Health at Newcastle University, the Centre director, was joined at the event by key speakers including Professor Jim Mann (Professor of Human Nutrition and Medicine at the University of Otago), Dr Benoit Varenne (WHO Oral Health Programme Officer) and Professor Srinath Reddy (President of the Public Health Foundation of India and the World Heart Federation).

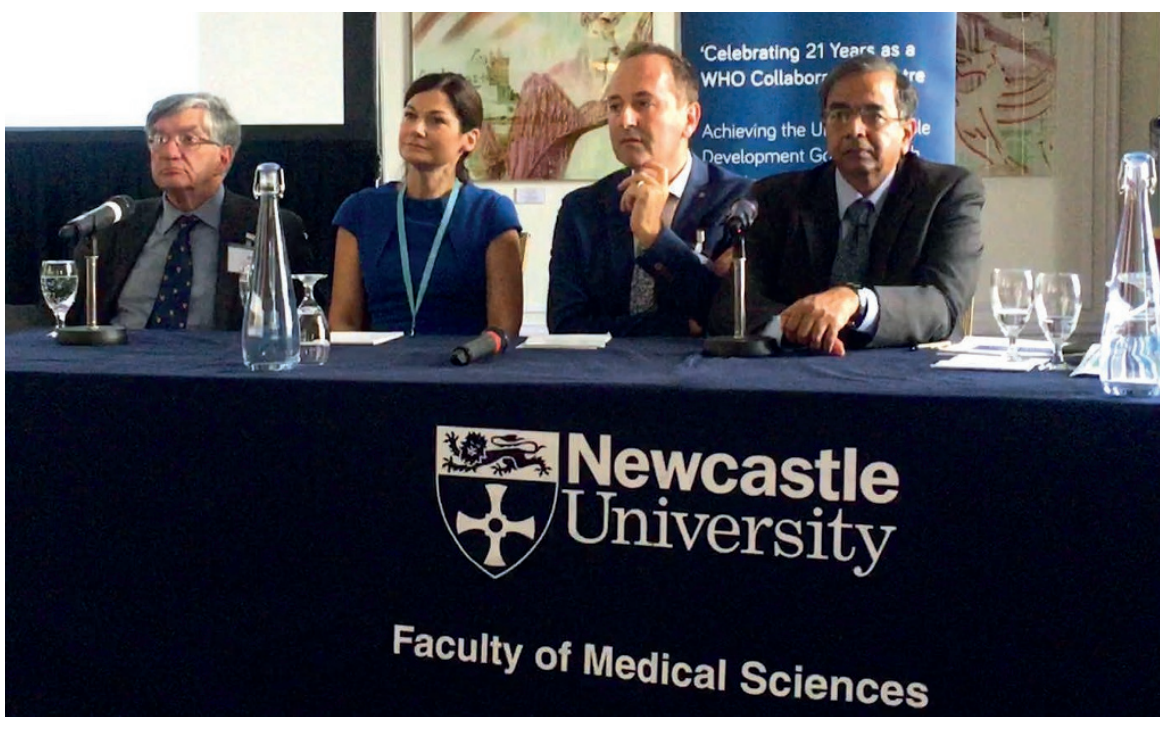

(Left to right) Professor Jim Mann, Professor Paula Moynihan, Dr Benoit Varenne, Professor Srinath Reddy

The event was held at BMA House in London and talks were followed by a panel discussion and a reception.

The WHO Collaborating Centre helps WHO to strengthen research capacity in the area of diet, nutrition and oral health and in implementing policy on non-communicable diseases common risk factor approaches, diet and nutrition, and oral health promotion.

The Centre was founded by Professor Andrew Rugg-Gunn, Emeritus Professor of Newcastle, in 1996 and is one of the longest standing collaborating centres in oral health. 